\title{
Delivering person centred care in long term conditions
}

Transforming care for people with long term conditions, including support for self management, requires comprehensive reform of health systems largely geared to provide acute care. Simon Eaton, Sue Roberts, and Bridget Turner explore the barriers to change, arguing that the success of new approaches will depend on whole system change and strong leadership

\author{
Simon Eaton clinical lead ${ }^{1}$, Sue Roberts chair ${ }^{1}$, Bridget Turner director of policy and care \\ improvement $^{2}$
}

${ }^{1}$ Year of Care Partnerships, Northumbria Healthcare NHS Foundation Trust, North Shields NE29 8NH, UK; ${ }^{2}$ Diabetes UK, London NW1 7AA, UK

Long term conditions are a major challenge to the sustainability of health services globally. ${ }^{1}$ Their increasing prevalence is associated with growing rates of preventable complications and premature mortality, resulting in soaring costs (box 1)..$^{2-5}$ These factors, coupled with higher expectations among patients and the public, ${ }^{6}$ create an urgent need to redesign health services, which are still largely geared to providing episodic acute care. ${ }^{78}$ Definitions of long term conditions as "health problems that require ongoing management over a period of years or decades" fail to reflect the personal, social, and economic burden on the individual, their families, and wider community. Nor do they acknowledge that people with long term conditions spend just a few hours a year interacting with clinicians and healthcare services and more than $99 \%$ of their lives managing their conditions themselves. The challenges they face vary widely depending on their personal circumstances; the number, nature, and stages of their conditions; the need for lifestyle, specialist, and technical interventions; and their capacity to self manage effectively. ${ }^{10}{ }^{11}$ Individual priorities and goals also differ and may often extend beyond a condition specific or health focus, particularly for the increasing percentage of people living with multimorbidity or frailty.

It is widely agreed that person centred services for people with long term conditions should be coordinated; support self management; engage people in decisions; provide effective prevention, early diagnosis, and intervention; and offer emotional, psychological, and practical support. ${ }^{6}$ More needs to be done to realise the untapped potential of patient led care through increasing tailored information, education, and training; access to new technologies; and peer and community support. ${ }^{1213}$ Accumulating evidence and experience shows that people who are "activated"- that is, have the knowledge, skills, and confidence to manage their health effectively_are more likely to adopt healthy behaviours and have better health outcomes and care experiences. ${ }^{11}$ This may lead to better use of resources. ${ }^{11}$ Thus, health services need to provide a comprehensive and coordinated range of interventions for populations but organised to provide a tailored response for each person. This requires fundamentally new ways of thinking about service delivery and relationships, recognising that whole system approaches are needed with support for self management as the central component, as set out in the chronic care model. ${ }^{14}$ Recent comprehensive programmes of care, such as TEAMcare in the United States ${ }^{15}$ and the Flinders programme in Australia, ${ }^{16}$ show that system wide organisational change can be achieved and improve clinical and personal outcomes.

\section{Challenges and barriers}

The barriers to introducing such whole scale change are, however, immense. A recent evaluation of a failed attempt to do this in the UK shows that the way change is introduced is vital. ${ }^{17}$ A top down approach, without clinical or management engagement and leadership, and failure to change attitudes from a biomedical and paternalistic approach, meant that support for self management was perceived as irrelevant and received little priority from staff or patients.

Clinicians' mindset and approaches are important in effecting change. Many clinicians believe they already practise in a patient centred way, though patient surveys tell otherwise. ${ }^{10}{ }^{18}$ Some don't see support for self management as their responsibility or find the shift in the relationship and power dynamic uncomfortable. ${ }^{17}{ }^{19}$ Guidelines and financial incentives focusing on disease specific biomedical approaches and misperception about lack of benefit support a climate of inertia. ${ }^{20}$ Limited consultation time and workload pressures also make it hard to explore new ways of working. 


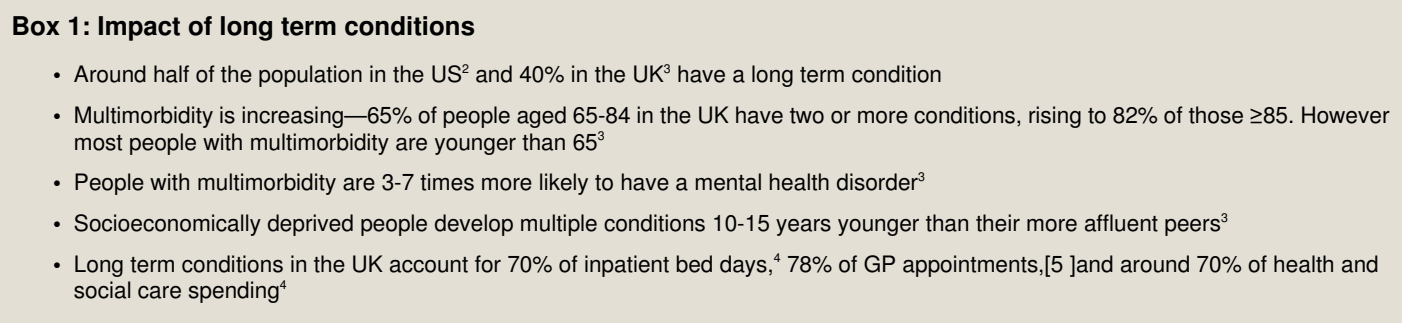

A further challenge is how services and clinicians respond to the diversity of individual needs and engagement in healthcare. For people already taking, or keen to take, a proactive and informed role, the traditional "clinician knows best" approach is frustrating. ${ }^{21}$ At the other end of the spectrum, around $40 \%$ of people report a poor understanding of their conditions or treatments, are lacking in confidence, or feel overwhelmed by the complexities of daily living. ${ }^{22}{ }^{23}$ Nevertheless, these individuals are still managing their health day to day and have the most to gain from additional support ${ }^{11}$ — colluding by continuing prescriptive approaches merely perpetuates poor outcomes and experiences.

Finally, we need to consider how change can be implemented at the pace and scale that is required. International evidence on the benefit of whole system approaches mainly comes from initiatives for specific conditions or within single organisations..$^{14-16}{ }^{24}$ However, in the UK people experience healthcare through multiple devolved teams facing conflicting incentives and drivers, with a focus on short term financial targets and surrogate outcomes rather than patients' priorities. This encourages discrete, narrowly focused interventions rather than the whole system approaches that may have greater overall benefit. ${ }^{25}$

\section{Care and support planning}

Focusing on policy and culture is unlikely to lead to change unless there are practical approaches that clinical teams can understand and implement. The "house of care" has received prominence in the UK as a practical framework for a whole system population approach that can deliver a unique and coordinated response for each individual. ${ }^{26}{ }^{27}$ At its heart is care and support planning — a "better conversation" that meets the demands of people to "plan my care with people who work together to understand me and my carer(s), allow me control, and bring together services to achieve the outcomes important to me." 28

Care and support planning is an ongoing, often annual, process to take stock, look forward, identify personal needs and goals, discuss options, and agree and coordinate a plan for how these goals will be met (box 2). A recent Cochrane review showed the benefits of such an approach, including the core components of preparation, goal setting, action planning and review. ${ }^{29}$ The authors underline that this is fundamentally different from, but embedded within, routine care.

Implementing care and support planning involves considerable organisational, skills, and attitudinal changes across the health community. The house of care provides a mechanism to achieve this (figure $\downarrow$ ). It is not a fixed model to impose on clinical teams or organisations, but has several defining properties. As a metaphor, it emphasises the importance and interdependence of each element, with care and support planning at its heart. As a checklist, it can stimulate reflection on the "building blocks" available locally, areas needing improvement, and components that are missing. Finally, as an organising framework, it also provides a reproducible and flexible tool to engage clinical teams and local communities with the principles of the chronic care model ${ }^{14}$ in a way that both feels achievable and enables them to see their role within the change process.

The house of care was initially tested in diabetes by primary care teams as part of the year of care programme,${ }^{30}$ but increasing experience suggests it can improve the care of people with multiple conditions (www.yearofcare.co.uk). The clinician training curriculum, which explores attitudes, behaviours, and clinic infrastructure changes simultaneously with skills, has shown that complex transformational change can occur in UK general practice enabling care and support planning to become the norm for large numbers people with long term conditions (box 3).

\section{Moving forwards}

Transforming support for people with long term conditions makes sense from every angle: improving wellbeing, developing a more positive sense of control, achieving better health outcomes, and potentially lower healthcare costs. It now seems possible to envisage this as the norm but substantial barriers and challenges exist. We need clinical and patient leadership to help navigate these challenges, along with system drivers and incentives, and practical support to encourage these new ways of working. People with lower activation levels, poor health literacy, and difficult social circumstances need specific and tailored support but have the most to gain. ${ }^{11} \mathrm{We}$ believe that the success of any clinician, team, or organisation should be defined by their efforts to tackle these disadvantages and to ensure a person's goals and priorities are always at the centre of his or her care.

We thank the health communities and other partners that have contributed to the learning from the year of care programme. We also thank Angela Coulter and Alf Collins for helpful comments.

Contributors and sources: SE is a consultant physician and diabetologist at Northumbria Healthcare NHS Foundation Trust. SR is a retired physician and former national clinical director for diabetes at the Department of Health. BT has type 1 diabetes and is director of policy and care improvement at Diabetes UK. All authors were involved in the development of the year of care programme and contributed equally to the article. SE is guarantor.

Competing interests: We have read and understood BMJ policy on declaration of interests and declare: SE and SR are currently employed by Year of Care Partnerships, a not for profit NHS organisation that supports organisations implementing care and support planning, hosted by Northumbria Healthcare NHS Foundation Trust.

Provenance and peer review: Commissioned; not externally peer reviewed.

UN Secretary General. Prevention and control of non-communicable diseases. UN General Assembly, 2011. www.un.org/ga/search/view doc.asp?symbol=A/66/83\&Lang=E. Ward BW, Schiller JS, Goodman RA. Multiple chronic conditions among US adults: a 2012 update. Prev Chronic Dis 2014;11:e62. 


\section{Box 2: Systematic care and support planning ${ }^{28}$}

Preparation-Most of us would feel uneasy about going into an important meeting and making snap decisions without having had a chance to think it through, yet we expect people to do this in the healthcare setting. Providing people with test results and prompts to list questions or things they'd like to cover beforehand may encourage greater participation

Discussion-The subsequent consultation should enable the person to articulate what is important to them, identify needs and priorities, define their goals, and agree a plan for how these goals will be met. This should recognise the mutual expertise of the person and the clinician aiming to build self efficacy, promote problem solving, and support each individual's self management efforts.

Documentation-The outputs of the consultation are summarised into a care plan that is owned by the person and also recorded in the clinical record and shared with other professionals as needed

Review—Next steps should be agreed, including a date for review, follow-up plans, and clear guidance on whom to contact for support in the interim

\section{Box 3: Examples of house of care approach to care and support planning \\ Whole health community-Tower Hamlets, London, UK}

As part of a wider reorganisation, care and support planning was implemented for diabetes in 31 of 32 practices in Tower Hamlets, which has a disadvantaged, multiethnic population. Local community events, faith groups, and advocates supported people with poor health literacy, including through pre-appointment health education sessions. After patients attended for diabetes "tests and tasks" they were sent colour coded tests results and prompts before a consultation with the GP or practice nurse around two weeks later. Over $90 \%$ of patients with type 2 diabetes had an annual care and support planning review and patient reported "involvement in care" rose from $52 \%$ to $82 \%$. Diabetes outcome measures and staff job satisfaction improved. Extended appointment time for the care planning consultation was recouped through practice reorganisation and was cost neutral overall. ${ }^{30}$

Multimorbidity-Holmside Medical Group, Newcastle, UK

In 2012, this 9000 patient, inner city practice implemented a single care and support planning process for anyone with one or more long term conditions. Year of care training was followed by practice facilitation and bespoke in-house training developing generic skills for nurses who had been condition specific. Patients were informed of the new system by leaflets, inserts with prescriptions, and discussion with receptionists and other practice staff. Recall systems were redesigned to offer patients a review in their birth month. Annual care and support planning discussions are now routine for all patients with long term conditions using the four stage approach (box 2). Practice time is used more effectively with no extra resource required; informal evaluation shows both patient and staff satisfaction has increased.

3 Barnett K, Mercer SW, Norbury M, Watt G, Wyke S, Guthrie B. Epidemiology of multimorbidity and implications for health care, research, and medical education: a cross-sectional study. Lancet 2012;380:37-43.

4 Department of Health. Long term conditions compendium of information. 2012 www.gov. uk/government/uploads/system/uploads/attachment_data/file/216528/dh_134486.pdf.

5 Salisbury C, Johnson L, Purdy S, Valderas JM, Montgomery AA. Epidemiology and impact of multimorbidity in primary care: a retrospective cohort study. Br J Gen Pract 2011;61:e12-21.

6 Richmond Group of Charities, King's Fund. From vision to action: Making patient-centred care a reality. 2012. www.kingsfund.org.uk/sites/files/kf/field/field publication file/ Richmond-group-from-vision-to-action-april-2012-1.pdf.

7 Tinetti ME, Fried TR, Boyd CM. Designing health care for the most common chronic condition一multimorbidity. JAMA 2012;307:2493-4.

8 NHS England. Five year forward view. NHS England, 2014. www.england.nhs.uk/wpcontent/uploads/2014/10/5yfv-web.pdf.

9 WHO. Preventing chronic diseases. Preparing a health care workforce. 2005. www.who. int/chp/knowledge/publications/workforce report.pdf.

10 Coulter A. Engaging patients in healthcare. Open University Press, 2011

11 Hibbard JH, Greene J. What the evidence shows about patient activation: better health outcomes and care experiences; fewer data on costs. Health Aff 2013;32:207-14.

12 Health Foundation. Helping people help themselves. 2011. www.health.org.uk/publications/ evidence-helping-people-help-themselves/.

13 NESTA. The business case for people powered health. 2013. www.nesta.org.uk/sites default/files/the_business_case_for_people_powered_health.pdf.

14 Wagner EH, Austin BT, Von Korff M. Organizing care for patients with chronic illness. Milbank Q 1996;74:511-44.

15 Katon WJ, Lin EH, Von Korff M, Ciechanowski P, Ludman EJ, Young B, et al. Collaborative care for patients with depression and chronic illnesses. N Engl J Med 2010;363:2611-20.

16 Battersby M, Harvey P, Mills PD, Kalucy E, Pols RG, Frith PA, et al. SA HealthPlus: a controlled trial of a statewide application of a generic model of chronic illness care. Milbank Q 2007;85:37-67.

17 Kennedy A, Rogers A, Chew-Graham C, Blakeman T, Bowen R, Gardner C, et al. Implementation of a self-management support approach (WISE) across a health system: a process evaluation explaining what did and did not work for organisations, clinicians and patients. Implement Sci 2014:9:129.
18 Healthcare Commission. Managing diabetes: improving services for people with diabetes. 2007. www.yearofcare.co.uk/sites/default/files/pdfs/Managing_diabetes.pdf.

19 Blakeman T, Macdonald W, Bower P, Gately C, Chew-Graham C. A qualitative study of GPs' attitudes to self-management of chronic disease. Br J Gen Pract 2006:56:407-14.

20 Chew-Graham C, Hunter C, Langer S, Stenhoff A, Drinkwater J, Guthrie EA, et al. How $\mathrm{QOF}$ is shaping primary care review consultations: a longitudinal qualitative study. BMC Fam Pract 2013;14:103.

21 Snow R, Humphrey C, Sandall J. What happens when patients know more than their doctors? Experiences of health interactions after diabetes patient education: a qualitative patient-led study. BMJ Open 2013;3:e003583.

22 Ellins J, Coulter A. How engaged are people in their health care? Picker Institute, 2005. www.health.org.uk/public/cms/75/76/313/3834/How\%20engaged\%20are\%20people\% 20in\%20their\%20healthcare\%20full\%20report.pdf?real Name=vqk1xh.pdf.

23 Hibbard $\mathrm{J} \mathrm{H}$, Cunningham PJ. How engaged are consumers in the health and health care, and why does it matter? Res Brief 2008;8:1-9.

24 Bloem BR, Munneke M. Revolutionising management of chronic disease: the ParkinsonNet approach. BMJ 2014;348:g1838.

25 Kennedy A, Rogers A, Bower P. Support for self care for patients with chronic disease. BMJ 2007;335:968-70.

26 Coulter A, Roberts S, Dixon A. Delivering better services for people with long-term conditions. 2013. www.kingsfund.org.uk/publications/delivering-better-services-peoplelong-term-conditions.

27 NHS England. Enhancing the quality of life for people living with long term conditions-the house of care. 2014. www.england.nhs.uk/house-of-care/.

28 National Voices. Principles of care and support planning. 2013. www.nationalvoices.org. uk/principles-care-support-planning.

29 Coulter A, Entwistle V, Eccles A, Ryan S, Shepperd S, Perera R. Personalised care planning for adults with chronic or long-term conditions. Cochrane Database Syst Rev 2015;1:CD010523.

30 Year of Care. Report of findings from the pilot programme. 2011 www.yearofcare.co.uk/ sites/default/files/images/YOC_Report\%20-\%20correct.pdf.

\section{Cite this as: BMJ 2015;350:h181}

(c) BMJ Publishing Group Ltd 2015 


\section{Figure}

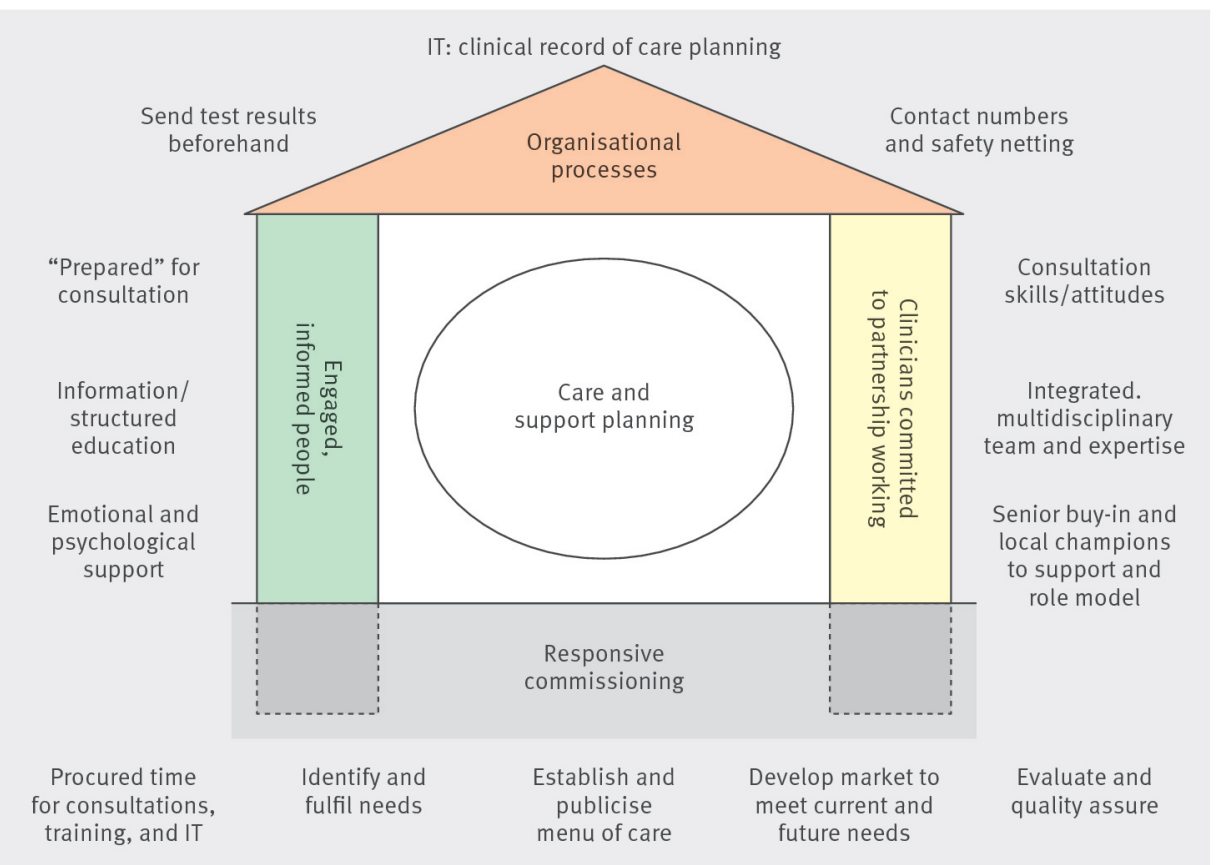

House of care. When used in the training programme, a blank outline of the house is provided and participants are asked to consider what needs to be in place to deliver and support the care planning process and then reflect on current local services. The examples shown here are those that have been consistently identified by teams across multiple diverse health communities $^{30}$ 